Revista de la Escuela de Ciencias de la Educación. 2022, Año 18 1(17). 61-77. Enero a junio. Schwamberger, C. Lo que la pandemia nos quitó: relatos de estudiantes con discapacidad intelectual en tiempos de COVID-19.

\title{
LO QUE LA PANDEMIA NOS QUITÓ: RELATOS DE ESTUDIANTES CON DISCAPACIDAD INTELECTUAL EN TIEMPOS DE COVID-19
}

WHAT THE PANDEMIC TOOK FROM US: STORIES FROM STUDENTS WITH INTELLECTUAL DISABILITIES IN COVID-19 TIMES

\author{
Cintia Schwamberger \\ Universidad Nacional de San Martín - CONICET, Argentina \\ cintiaschwambergerger@gmail.com
}

Recibido: 16 de julio de 2021 Aprobado: 9 de septiembre de 2021 Publicado: 31 de diciembre de 2021

Cita sugerida: Schwamberger, C. (2022). Lo que la pandemia nos quitó: relatos de estudiantes con discapacidad intelectual en tiempos de COVID-19. Revista de la Escuela de Ciencias de la Educación 1(17) 61-77.

\section{RESUMEN}

El presente artículo tiene como objetivo relatar la experiencia de estudiantes con discapacidad intelectual en escuelas secundarias emplazadas en contexto de pobreza urbana de la Región Metropolitana de Buenos Aires. Desde una metodología cualitativa nos centramos en las voces de dos estudiantes que narran su experiencia escolar en tiempos de confinamiento. Sostenemos que se vuelve clave recuperar las voces de quienes son destinatarios de las políticas de inclusión que asumen, en tiempos de neoliberalismo recargado, una práctica cosmética como forma de solapamiento de las desigualdades que viven a diario las personas con discapacidad. En rigor, esto no es nuevo, sino que, los efectos y afectos de las políticas profundizaron las marcas de exclusión que vivió el colectivo en tiempos de COVID-19. Esta situación conduce a la necesidad de analizar y poner en discusión las condiciones materiales que habitan y cómo se desarrolla la escolaridad. En los relatos se evidencian las tensiones atravesadas, en tiempos de cuarentena, en tanto que obstáculos, pero, a la vez, de distintas prácticas que les permitió desplegar sus potencias y habilidades.

Palabras clave: Discapacidad intelectual - Inclusión - Pandemia - Escuela Secundaria. 
Revista de la Escuela de Ciencias de la Educación. 2022, Año 18 1(17). 61-77. Enero a junio. Schwamberger, C. Lo que la pandemia nos quitó: relatos de estudiantes con discapacidad intelectual en tiempos de COVID-19.

\section{ABSTRACT}

This article aims to report the experience of students with intellectual disabilities who go through their schooling in secondary schools located in contexts of urban poverty in the Metropolitan Region of Buenos Aires. From a qualitative methodology, we focus on the voices of two students who narrate their school experience in times of confinement. We argue that it is essential to recover the voices of those who are recipients of inclusion policies that assume, in times of overloaded neoliberalism, a cosmetic practice as a form of overlapping of the inequalities that people with disabilities experience every day. Strictly speaking, this is not new, but rather, the effects and effects of the policies deepened the marks of exclusion that the group experienced in times of COVID-19. This situation leads to the need to analyze and discuss the material conditions they inhabit and how schooling is developed. In the stories, the tensions they experienced are evident, in times of quarantine, as obstacles but, at the same time, of different practices that allowed them to display their powers and abilities.

Keywords: Intellectual Disability - Inclusion - Pandemic - Secondary School.

\section{INTRODUCCIÓN}

Walter Benjamin en El narrador (1991), advierte sobre lo ocurrido a partir de la Guerra Mundial en la que los soldados cuando regresaban de la batalla de trincheras -si es que lo hacían- la posibilidad de narrar lo acontecido se interrumpía, se silenciaba, se "enmudecía" (p.60). En su obra propone un análisis sobre la diferencia entre la posibilidad de que existan narraciones respecto de la información y presta particular atención a la figura de la muerte. En este sentido, la narración para Benjamin es una posibilidad artesanal, una capacidad de relatar la experiencia -enmudecida en estos casos- que surge a través de los hechos traumáticos vividos. Esos hechos traumáticos que debaten al hombre, entre la vida y la muerte, lejos de querer realizar una homologación lineal y directa de la situación de las guerras mundiales con el COVID-19, nos encontramos, con algunos de esos modos inenarrables que la experiencia en tiempos de pandemia nos trajo aparejado. Nos referimos a relatos de finitud de los cuerpos, pero también de la fragilidad de las vidas. Valorizar la experiencia de narrar aquello que nos pasa y nos pasó refiere justamente a recuperar los modos eternos, en término de Benjamin (1991, p.26), de la historia y su posibilidad de rememorarla. Para ello, es vital que la narración sea posible, tome fuerza y haya quiénes estén dispuestos a escucharla y retrasmitirla. Es justamente eso que nos distingue como humanos en tanto posibilidad de acción, pero también de la producción de un discurso único, irrepetible y plural. Es así que gracias a la posibilidad de narrar(nos), podemos saber quiénes somos.

Aquí nos centramos en esa posibilidad de narrar experiencias de estudiantes con discapacidad que realizan sus trayectorias en escuelas secundarias a partir de valorar aquello que tienen para decir sobre lo que significó atravesar la pandemia en sus hogares, con sus familias, con la escolaridad a través de la pantalla y con las múltiples barreras que debieron sortear. Lo 
Revista de la Escuela de Ciencias de la Educación. 2022, Año 18 1(17). 61-77. Enero a junio. Schwamberger, C. Lo que la pandemia nos quitó: relatos de estudiantes con discapacidad intelectual en tiempos de COVID-19.

anterior, deviene relevante porque muchas veces esa experiencia resulta silenciada y aminorada. Esto ocurre, especialmente cuando se trata de estudiantes con discapacidad intelectual. En ese punto, Gerber (2008) menciona que esas voces no son legitimadas ni ubicadas en un lugar de autoridad, respecto de otros grupos excluidos, incluso al interior de la propia discapacidad, y de los discursos de especialistas o académicos,

La negativa de una voz a las personas con discapacidad fue aún más determinante en el caso de aquellas clasificadas como "retrasadas mentales" por nuestro criterio históricamente cambiante. (...) Esta clasificación trajo consigo el entendimiento de que esos individuos carecen de la capacidad de aprender y razonar ¿cómo se puede entonces admitir una voz de esas características en una discusión significativa sobre algo que vaya más allá de las necesidades más básicas y urgentes? (p. 276).

Alejados del término que utiliza para referirse a las personas como "retrasadas mentales", en base a las discusiones y modificaciones que surgieron a lo largo de los años, sostenemos aquí que las personas nucleadas bajo esta categoría se configuran como lo abyecto de lo abyecto (Schwamberger y Grinberg, 2020, p. 5). Es decir, como cuerpos incognoscibles y amenazantes que desestabilizan los parámetros de la ideología de la normalidad(Rosato y Angelino, 2009). Son aquellos cuerpos que quedan siempre en las últimas filas del reconocimiento en tanto sujetos con los mismos derechos que cualquier otro. Esto fue extensamente estudiado por Ferrante (2020), que acuñó el término categoría de segunda, para referir a la identidad que se otorga, en las sociedades contemporáneas, a los sujetos con discapacidad como formas de menosprecio social y que deviene, a la vez, en un proceso de deshumanización. Al respecto, Butler (2010), menciona que no todos los actos de reconocimiento son tales sino, que para que una vida sea considerada como vida tiene que inscribirse en ciertos parámetros o esquemas de inteligibilidad(p.21) natural y discursivamente dados. Al respecto en Cuerpos que importan se interroga:

¿Qué oposición podría ofrecer el ámbito de los excluidos y abyectos a la hegemonía simbólica que obligara a re articular radicalmente aquello que determina qué cuerpos importan, que estilos de vida se consideran "vida", qué vidas vale la pena proteger, qué vidas vale la pena salvar, qué vidas merecen que se llore su pérdida? (Butler, 2018, p. 39).

Sin embargo, la exclusión en términos de abyección, producida al interior de los propios colectivos de personas con discapacidad, se vuelve cada vez más notoria. En efecto, aquellas personas que poseen en sus cuerpos deficiencias cognitivas o intelectuales serán relegadas de cualquier beneficio en términos de políticas, como de los discursos y enunciados que descartan sus luchas históricas y las infravaloran. Esto se evidenció con más fuerza en tiempos de pandemia mediante formas de gobierno que no sólo magnificaron la exclusión sino, que invisibilizaron a las personas con discapacidad de los discursos y políticas destinadas al conjunto de la población en general. No sólo importa referirnos a esos discursos silenciados, sino, fundamentalmente, a lo modos crueles que los 
Revista de la Escuela de Ciencias de la Educación. 2022, Año 18 1(17). 61-77. Enero a junio. Schwamberger, C. Lo que la pandemia nos quitó: relatos de estudiantes con discapacidad intelectual en tiempos de COVID-19.

gobiernos centrales "sinceran" esas omisiones. Retomando a Butler (2010), "El problema no es meramente cómo incluir a más personas dentro de las normas ya existentes, sino considerar cómo las normas asignan reconocimiento de manera diferencial" (p. 20).

En ese reconocimiento diferencial y por ende desigual, que han sufrido históricamente las personas con discapacidad y, en particular, estudiantes con discapacidad intelectual, nos preguntamos ¿cómo realizar investigaciones que narren sus voces?, ¿cómo recuperar aquello que tienen para decir sobre sus vidas, sobre la sociedad y sobre las decisiones que toman por sobre ellas, sin caer en reduccionismos y homogeneizaciones universales, que escapen a cualquier codificación y segmentación de las experiencias vividas por las personas con discapacidad?. Asimismo, ¿cómo eludir la reproducción de discursos y enunciados hegemónicos que solapan y obstruyen cualquier posibilidad de expresión? Es por ello que, en este trabajo, recuperamos sus voces en términos de potencia a través de sus narraciones.

Los enunciados, saberes y prácticas adjudicadas a las personas con discapacidad estuvieron sometidas como menciona Walmsley (2008), "por la eugenesia, la psicología, los estudios educacionales y clínicos (...) donde se las examinó, contó, analizó, describió y, con frecuencia se les diagnosticó una patología, pero nunca les consultaron sobre sus puntos de vista" (p. 360). La investigación emancipadora, en el marco del modelo de producción materialista de la discapacidad (Barnes, 2008), arroja algunas pistas para centrar la mirada en procesos investigativos que involucren el compromiso de quién investiga y el modo de acercamiento a los sujetos con los que se realiza el trabajo de investigación. Como lo reconoce el autor este tipo de indagación demanda que,

(...) los análisis de las experiencias, escritos e historias de las personas con discapacidades se inserten claramente en un marco cultural y en un ámbito que pongan en evidencia las consecuencias "incapacitantes" de una sociedad organizada alrededor de las necesidades de una mítica gran mayoría de personas sin discapacidades (p. 389-390).

En este trabajo, intentamos romper con esas lógicas capacitistas para lograr acercarnos de manera hospitalaria y cuidada a cada una de las voces de estudiantes que narran su experiencia escolar. Al respecto, la pregunta política en estas propuestas se vincula con lo que afirman Levín Rojo y Denys Espinoza (2009), "¿Dónde queda, entonces, el que vive en condición de discapacidad -en particular la intelectual-?, ¿cómo puede constituirse en sujeto de su propio discurso?" (p. 142). En este sentido, producirse como sujeto político se vincula con aquello que Benjamín (1991) postula sobre la posibilidad de que existan narraciones en tanto que permite, por un lado, mantener la fuerza de los enunciados, desde los protagonistas, a la vez, que esa experiencia se hace carne y se multiplica. Es por ello que desde un enfoque cualitativo que recupera aportes de la metodología biográfico-narrativa (Porta, 2021; Suárez, 2007), describimos los modos de ser y estar en las escuelas secundarias públicas desde la perspectiva de dos estudiantes con discapacidad intelectual. Al respecto Moriña Diez (2010), resalta que los estudios que se centran a partir de esta matriz, 
Revista de la Escuela de Ciencias de la Educación. 2022, Año 18 1(17). 61-77. Enero a junio. Schwamberger, C. Lo que la pandemia nos quitó: relatos de estudiantes con discapacidad intelectual en tiempos de COVID-19.

(...) son una herramienta metodológica apropiada para denunciar y explicar los procesos de opresión, discriminación y exclusión que sufren algunos colectivos (...) que cuando se escuchan las voces de personas con discapacidad se contribuye al incremento de propuestas de mejora para caminar hacia una educación inclusiva (p. 671).

Con este trabajo entonces, intentamos poner en discusión las formas que adquiere la inclusión a partir de determinadas condiciones materiales que como rasgo principal se constituyen en términos de precariedad (Butler, 2006). No se trata en términos de la autora en utilizar esas palabras como propias sino, en posibilitar la comprensión del Otro que nos envuelve en una condición del Nosotros, en un aquí y ahora, cambiante y contingente. En ese nosotros, sostenemos que las políticas de inclusión asumen una práctica cosmética (Ferrante, 2020), como forma de solapamiento de las desigualdades que viven a diario las personas con discapacidad. En rigor, esto no es nuevo, sino, que, los efectos y afectos de las políticas profundizaron las marcas de exclusión que vivió el colectivo en tiempos de COVID-19 (Espinoza Parra; Maldonado Regalado y Rosero Poma, 2020; Grinberg y Verón, 2021). Esta situación conduce a la necesidad de analizar de manera pormenorizada las condiciones materiales en las que viven y en cómo se desarrolla la escolaridad.

El trabajo que aquí se presenta propone, en el primer apartado un breve estado de situación acerca de los procesos de inclusión de estudiantes con discapacidad en el nivel secundario. Seguidamente, se describe la propuesta metodológica en base a un estudio de carácter cualitativo a partir del relato experiencia de dos estudiantes con discapacidad intelectual en escuelas secundarias públicas de gestión estatal emplazadas en contexto de pobreza urbana. En los resultados se describen algunos de los obstáculos transitados y los apoyos obtenidos. Finalmente se abren interrogantes con el objeto de revisar los modos en que la inclusión de estudiantes con discapacidad ocurre efectivamente en las aulas.

\section{DESARROLLO}

\section{Breve estado de situación de la inclusión educativa en el nivel secundario}

Cuando hablamos de inclusión, nadie puede eludir su semántica ni su puesta en escena. La pregunta, más bien, es indagar no tanto sobre lo que es y no es la inclusión sino, el modo en que ella se produce al interior de las instituciones, así como los procesos de subjetivación que se dan en torno a ella (Thoma, Hillesheim, Coureiro Siqueira, 2019). Al respecto, Lopes (2011) sitúa la discusión entre estos diálogos y analiza el formato en que el estado neoliberal conduce hacia los imperativos de la inclusión como un:

(...) conjunto de prácticas que someten a los individuos a mirarse a sí mismos y al otro, basados en una división platónica de relaciones; también puede entenderse como una condición de vida en la lucha por el derecho a 
Revista de la Escuela de Ciencias de la Educación. 2022, Año 18 1(17). 61-77. Enero a junio. Schwamberger, C. Lo que la pandemia nos quitó: relatos de estudiantes con discapacidad intelectual en tiempos de COVID-19.

representarse, a participar en los espacios públicos, a ser contabilizado y alcanzado por las políticas de Estado (p.7) ${ }^{1}$.

Estar bajo el paraguas de la inclusión implica, como se problematiza en distintas investigaciones, desarrollar estrategias para gestionarla (Bocchio, Schwamberger, Armella y Grinberg, 2020) y, es allí donde comprende múltiples aristas y prácticas que discurren entre una tríada inseparable. Esto es, entre lo políticamente correcto, asociado a discursos entre el imperativo y deber ser de la inclusión; la posibilidad de cumplimentar la norma, lo que es jurídicamente aceptable y; el objeto principal de garantizar el derecho a la educación. Entre la norma, el discurso y su puesta en acto (Bochio, 2020), la inclusión encuentra un sinfín de recovecos. Algo de ello declaman los estudios que se realizan respecto de los organismos de gobierno.

En efecto, el último relevamiento anual del 2019, de la provincia de Buenos Aires, específicamente en la región del conurbano bonaerense, establece que un total de 22.500 estudiantes con discapacidad transitan su escolaridad en instituciones de educación común. El 75.71\% (17.036) lo hace en escuelas públicas de gestión estatal (15204), como en la modalidad de adultos (1832). Un porcentaje menor, el 24.29\% (5514), está escolarizado en circuitos de gestión privada. Sin embargo, a medida que se avanza en los niveles, la inclusión se desacelera. En nivel inicial se encuentran incluidos 1.276 estudiantes, en primaria $9.086 \mathrm{y}$, en secundaria 4.842. Asimismo, en adultos, modalidad que hay que prestar particular atención, ocurre el mismo efecto. En primaria transitan 693, en secundaria 354 y en técnico profesional lo hacen 785 estudiantes con discapacidad. Respecto de la región 7 en la que se ubican las escuelas, que concurren los estudiantes, sólo existen datos da la totalidad de la matrícula de educación especial (4.344), de los cuales 2.714 asisten a escuelas de gestión pública mientras que 1.630 lo hace en gestión privada.

La Secretaría de Investigación y Evaluación Educativa (2021), mediante un relevamiento sobre la continuidad pedagógica en pandemia encontró que el $45 \%$ de los y las docentes de nivel primario tienen a su cargo estudiantes con discapacidad. Realizan una progresión respecto de la tendencia en alza de dichos procesos que se ubica entre 2.8 y 3 puntos porcentuales cada año. Lo anterior, se debe en buena medida a las últimas resoluciones del Consejo Federal de Educación, en particular, la no. 311/16 que regula y orienta los procesos de evaluación, certificación y acreditación de los proyectos de inclusión en los distintos niveles y modalidades del sistema educativo. Un estudio sobre su implementación (UNICEF, 2020), estipula que el $67 \%$ de estudiantes con discapacidad recibe la titulación correspondiente a sus saberes, mientras que el $15 \%$ no lo hace $y$, el $18 \%$ restante se encuentra en un estado de ambigüedad.

Esta situación pone un punto de alarma, justamente, para indagar sobre cómo los procesos de inclusión en el nivel secundario ocurren. Lo anterior, como se observa en los datos del relevamiento anual se reducen drásticamente, a casi más de la mitad, respecto del nivel primario. Esto lo advierten diferentes investigaciones (Barrozo, 2018; Galván, 2018; Lanza y Dubrovsky, 2019; Schewe,

${ }^{1}$ La traducción es nuestra. 
Revista de la Escuela de Ciencias de la Educación. 2022, Año 18 1(17). 61-77. Enero a junio. Schwamberger, C. Lo que la pandemia nos quitó: relatos de estudiantes con discapacidad intelectual en tiempos de COVID-19.

2021), que ponen en discusión los procesos de inclusión, desde las voces de sus protagonistas, respecto del tránsito por el secundario. Situar la mirada en este nivel involucra una decisión política que tiene por objeto describir y analizar, desde la experiencia de los principales "benefactores" y "afectados", las formas particulares que adquieren los procesos de inclusión en las escuelas del nivel secundario. En particular, cuando los sujetos que encarnan la inclusión son estudiantes con discapacidad intelectual que habitan espacios de pobreza urbana. Lo anterior importa en profundidad, en tanto, como mencionan distintas investigaciones (Cinquegrani, 2021; Danel, 2021; Machado, 2020), se configura en un hacer que atraviesa a familias, sujetos e instituciones de manera desigual.

\section{Método}

\section{Diseño}

A partir de un estudio descriptivo, de carácter cualitativo (De Seena, 2015), nos centramos en las experiencias de dos estudiantes con discapacidad intelectual que transitan su escolaridad en dos escuelas secundarias, emplazadas en contexto de pobreza urbana, de una localidad de la Región Metropolitana de Buenos Aires. Ambas instituciones son de gestión pública y reciben estudiantes con distintos proyectos de inclusión. El término distintos refiere justamente a que los dispositivos que se despliegan en cada institución, responden a acuerdos y procesos institucionales que, si bien, guardan semejanzas, a partir de las legislaciones y resoluciones, su puesta en marcha (Bochio, 2020), difiere en función de las capacidades que cada escuela pueda desplegar, adquirir y desarrollar.

Los relatos que aquí reconstruimos resaltan el valor de la propia subjetividad de los participantes, que ha sido rechazada e infravalorada socialmente, en la cual, también, resignifican la propia experiencia transitada. Ello, por que como menciona Suarez (2007), la investigación narrativa se propone como un enfoque "que altera algunas certezas de los modos asentados de investigar, haciendo de esta práctica algo más accesible, natural y democrático" (p. 83). En efecto, recurrir a esta estrategia como postulan Connelly y Clandinin (1995), se vincula con la capacidad que tenemos los humanos de ser "contadores de historias, organismos que, individual y socialmente, vivimos vidas relatadas. (...) es la forma en que los seres humanos experimentamos el mundo" (p. 11).

En ese contar historias que no son narraciones individuales y aisladas, más bien, se constituyen como un relato que nos involucra, en tanto, como menciona Bolívar (2002), lo narrativo "prioriza un yo dialógico, (...) donde la subjetividad es una construcción social, intersubjetivamente conformada por el discurso comunicativo. $Y(\ldots)$, se convierte en un modo privilegiado de construir conocimiento" (p. 4). Creemos que este enfoque permite a quien investiga adentrarse en los múltiples mundos que los sujetos tienen/tenemos para contar. Narrar(nos) es, en suma, escapar al enmudecimiento (Benjamín, 1991).

\section{Participantes}

En este trabajo se encuentran las voces de Roby y Pablo, dos estudiantes varones, que transitan el primer y segundo año del nivel secundario, 
Revista de la Escuela de Ciencias de la Educación. 2022, Año 18 1(17). 61-77. Enero a junio. Schwamberger, C. Lo que la pandemia nos quitó: relatos de estudiantes con discapacidad intelectual en tiempos de COVID-19.

acompañados por un docente de apoyo a la inclusión. Ambos estudiantes habitan territorios de la urbe marcados por la pobreza urbana y la contaminación ambiental (Grinberg, 2020), en particular, sus hogares se asientan en las villas miseria que posee la localidad. Para resguardar su identidad, en los relatos, se utilizan nombres ficticios y cada una de los encuentros cuenta con el debido consentimiento informado, con el objeto de dar a conocer sus posicionamientos respecto de la inclusión en tiempos de pandemia. Los criterios de selección de los estudiantes refieren, en primera medida, al deseo de querer narrar y compartir su experiencia en pandemia. En segundo lugar, que estén transitando la escolaridad a través de los distintos dispositivos desplegados por las instituciones de nivel secundario $y$, tercero, que manejen dispositivos tecnológicos para concretar los encuentros -cara a cara- a través de la pantalla o el celular de forma independiente.

\section{Instrumentos}

Para acceder a la información se realizaron cuatro entrevistas individuales en profundidad (De Seena, 2015), a cada uno de los estudiantes en sus hogares por medio de video llamadas o audios por WhatsApp. La duración de cada una de ellas se desarrolló entre hora y media y dos horas. Algunos de estos encuentros se organizaron a partir de preguntas disparadoras mediante las cuales cada estudiante podía retratar a través de imágenes o palabras aquello que sentían y pensaban sobre la pandemia. Como menciona Trueba (en Porta, 2021), desde esta perspectiva, la entrevista no puede considerarse como una técnica estandarizada, sino que es "un encuentro de expansión de horizontes tanto para quien entrevista como para quien es entrevistadx" (p.373), en una perfecta "combinación de sensibilidad de y rigurosidad" (p. 375) a partir de la cual uno se afecta y es afectado por los otros (Yuni, 2021).

En el apartado de resultados se recuperan algunas de estas maravillosas producciones. Esta estrategia radica justamente en habilitar otros modos de narrar y de "obtener" información que se produce en el acto investigativo. Implica centrar al sujeto con discapacidad intelectual, en el foco de la cuestión, como sujeto activo de su propio transitar y de construir su relato. Asimismo, recuperar sus historias a través del dibujo o la escritura permite acercarnos también al lugar del detalle como señala Geertz (2003), pero un detalle que es producido y analizado en primera persona.

\section{Procedimiento y análisis de datos}

El proceso de categorización y análisis de la información, se diagramó a partir del método de comparación constante (Glaser y Strauss, 1967), contextualizando y descontextualizando la información, con el objeto de encontrar regularidades en los relatos. Las categorías permiten acercarnos a los modos en que los estudiantes, han transitado la escolaridad en tiempos de pandemia. Esto se produce a partir de la sistematización de los relatos mediante el análisis de los discursos de manera general y luego en profundidad con el objeto de lograr establecer conjuntos de categorías que respondan a los objetivos del estudio.

Estas categorías iniciales se discutieron con los estudiantes para luego profundizar, a partir de ellas, e ir hacia nuevas conceptualizaciones. Al respecto, 
Revista de la Escuela de Ciencias de la Educación. 2022, Año 18 1(17). 61-77. Enero a junio. Schwamberger, C. Lo que la pandemia nos quitó: relatos de estudiantes con discapacidad intelectual en tiempos de COVID-19.

las categorías emergentes se refieren en particular: tránsito de la escolaridad antes, durante y después de la pandemia; los obstáculos y los apoyos recibidos desde las escuelas que los acompañan; el lugar de la familia; los encuentros virtuales con pares y docentes; los deseos de volver a la escuela y, lo que esperan de la escuela en el futuro (Machado, 2020).

\section{Resultados}

A partir del análisis y categorización de las narrativas de los estudiantes nos centramos en dos ejes nodales respecto de los obstáculos transitados durante la pandemia y las oportunidades que ella trajo consigo.

\section{Obstáculos en cuarentena}

En uno de los primeros encuentros realizados junto a los estudiantes, la conversación versó sobre aquello que la pandemia les había quitado y no les permitía hacer. La motivación fue realizar una intervención gráfica que identifique esos puntos limitantes de la pandemia. Uno de ellos, Pablo, decidió realizar un dibujo de un barbijo con distintos mensajes "escritos en su interior" tal como sigue en la siguiente figura:

Figura 1. Barbijos Out

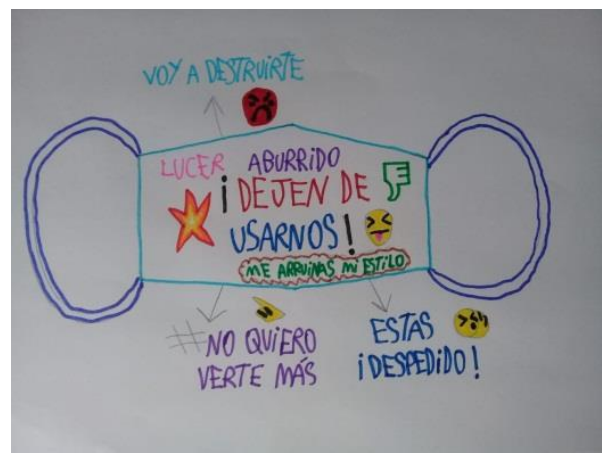

Fuente: Pablo, estudiante con discapacidad

El estudiante decide centrar su atención en el uso de los barbijos. Como disfruta realizar expresiones gráficas y en ciencias sociales es una práctica de indagación que, desde las últimas décadas, toma fuerza (Grinberg y Armella, 2021), se utiliza este lenguaje para desplegar sus deseos e inquietudes. Los mensajes que escribe en su interior se vinculan con ese deseo, el de muchos seguramente, de no utilizarlos más. Al respecto, decide titular a su producción como Barbijos Out. En ese barbijo escribe mensajes como " voy a destruirte, lucer (tal como lo escribe el estudiante), aburrido, iDejen de Usarnos!, Me arruinas mi estilo, \#No quiero verte más y, estás despedido". Frases significativas que se vinculan con la necesidad de no usar más los barbijos y el modo en que ello repercute en los procesos de socialización y subjetivación que el estudiante transita. A partir de esta producción, se indaga por el motivo de su negación a usar esta medida de protección. Ante esto, su mirada es de asombro y contesta lo siguiente: 
Revista de la Escuela de Ciencias de la Educación. 2022, Año 18 1(17). 61-77. Enero a junio. Schwamberger, C. Lo que la pandemia nos quitó: relatos de estudiantes con discapacidad intelectual en tiempos de COVID-19.

claro porque no puedo saludar a la gente como quiero, porque no nos escuchamos bien y a veces me pierdo cuando una maestra está hablando o cuando alguien en la calle me pregunta algo y porque no me gusta. No me deja ver las caras de la gente (Pablo, mayo de 2021).

Este relato condensa varios de los puntos centrales que Skliar (2011), menciona sobre la necesidad de pensar la educación y la inclusión en términos de "gestos mínimos" (p.15) que involucra "dar la bienvenida, saludar, acompañar, permitir, ser paciente, posibilitar, dejar, ceder, dar, mirar, leer, jugar, habilitar, atender, escuchar" (p.18). Gestos que, como menciona, no pretenden ser grandes reformas ni transformaciones curriculares sino, justamente "educar no ya a todos, en sentido abstracto, sino a cualquiera y a cada uno" (p. 18). Esas escenas de hospitalidad, reconocimiento y gesto colectivo se vinculan con la necesidad que menciona Pablo, de saludar y dar la bienvenida, poder escuchar(nos) y ver(nos) los rostros, los gestos, las miradas. Esa rostridad estudiada ampliamente por Levinas (1993), en tanto que se constituye como parte de un vínculo que ordena, afecta y nos transforma en sujetos responsables en el devenir de la vida.

Respecto de lo que menciona Pablo sobre "perderse cuando la maestra habla" se dispone como uno de los obstáculos para transitar la escolaridad y el estudiante menciona:

Si, es difícil para mí escuchar a la profe con el barbijo puesto. Me pierdo, si no está la maestra que me ayuda, a veces no llego a copiar. Cuando estoy en la video llamada, no hay buena señal, no escucho, es más difícil estudiar así. Quiero que sea todo como antes, sin barbijos, sin alcohol, sin distancia (Pablo, mayo de 2021).

Sostener procesos de inclusión, en este nivel, como mencionan las investigaciones relevadas, nos encuentra con estos nuevos obstáculos referidos a las modalidades que asume la escolaridad en el presente. Estar en la escuela de manera presencial implica perderse entre las voces de sus docentes, porque usan barbijo y no los escucha, a la vez, que, en la virtualidad, sus problemas de conectividad y dispositivos, obstaculizan su proceso de enseñanza y aprendizaje que, como él menciona "es más difícil estudiar asf'. En efecto, esa frase condensa los límites que la inclusión en tiempos de pandemia, trajo consigo.

Como mencionamos, la negación al uso del barbijo se establece en ese necesitar(nos), al mismo tiempo, nos encontramos con otros relatos respecto de la tensión entre ese necesitar(nos) y salvaguardar la vida en este contexto. En ese punto, hallamos otra de las necesidades de los estudiantes, en este caso de Roby, respecto de la decisión ministerial de retornar a las clases en las aulas de manera bimodal:

cuando comenzó el COVID nos fuimos todos a zoom y lo hicimos todo con zoom. Estábamos perfectamente con el zoom hasta que llegó el momento de ir otra vez a la escuela, pero yo no estaba seguro porque el covid estaba siguiendo infectando y matando gente. ¿Entendés?, a mí no me gustaba ir a la escuela con 
Revista de la Escuela de Ciencias de la Educación. 2022, Año 18 1(17). 61-77. Enero a junio. Schwamberger, C. Lo que la pandemia nos quitó: relatos de estudiantes con discapacidad intelectual en tiempos de COVID-19.

el covid yo quería seguir con el zoom. Yo quería el zoom. Pero bueno obligación ir a la escuela (Roby, abril de 2021).

Estar perfectamente con el zoom implica, para este estudiante, cuidarse aún más del contagio. Aquí es dónde los debates entre presencialidad si y presencialidad no, se diluyen. Roby manifiesta no querer ir a la escuela, pero tiene que hacerlo por obligación, porque sabe a ciencia cierta lo que ocurre cuando los cuerpos son afectados por este virus:

Porque estuve muy mal. Vomité, bajé de peso, un montón. Como no sentía, perdí el sentido el olfato y el gusto. Como no sentía el gusto no me gustaba la comida. Entonces no comí nada, vos te acordás lo flaco que era (...) Pero estoy bien. Mi papá fue el primero que empeoró mal y después yo, yo fui más peor. La fiebre se me subía a cada rato y no bajaba. Me llevaron al hospital y me querían dejar internado pero mi mama no quería porque me iban a llenar de pinchazos y no quería estar en casa sola sin mí. (...) Entonces me quedé encerrado en mi pieza y acá me mejoré. Pero estoy mejor, sí me siento mejor, no tengo moco nada y eso. Me alegro de haber mejorado acá en casa porque no sabía si iba a avanzar bien, pero avance muy bien por suerte y sigo avanzando (Roby, abril de 2021).

Estos tiempos no sólo nos han quitado los rostros, las sonrisas, la presencialidad en la escuela, sino, que, de manera magnificada la muerte estuvo más latente y sigilosa como nunca antes. Acechó en todos los órdenes de la vida, en la nuestra, en la de nuestros seres queridos, compañeros y vecinos. Roby, como tantas familias y estudiantes deciden no arriesgarse, en este caso, a encontrarse con el virus y padecer los designios de la internación y sus prácticas deshumanizantes. Entre tantas preocupaciones y entre las narraciones de los estudiantes nos topamos con otros decires, respecto de lo que la pandemia nos quitó, pero en su anverso. Nos enfocamos en el segundo eje de análisis centrado en las oportunidades en tiempos de cuarentena.

\section{Oportunidades en cuarentena}

Debates suscitados, en relación sobre si la pandemia nos hace mejores o nos trae algunos beneficios, algunos autores se aventuraron a problematizarlo. Echeíta (2020), referente en términos de educación inclusiva, se pregunta justamente si el Covid-19 es una oportunidad para revisar las prácticas, los sistemas educativos y menciona que, "Cuando salgamos de la batalla (...), sabremos la respuesta que, individual y colectivamente, habremos dado a estos y a otros importantes interrogantes que en estos días de confinamiento afloran como urgentes y necesarios" (p.11). Al respecto Roby nos ofrece su mirada:

Te digo que gracias al COVID- gracias, te digo que no existiría el zoom y no existiría ni la amistad ni el vínculo que hicimos con otros alumnos. Hicimos vínculo, hicimos juegos, un montón de cosas. Eso me encantó. Si no fuera por el COVID no existiría el ZOOM para nosotros y tengo que agradecer que, aunque infectó y mató personas tengo que agradecer que gracias al COVID inició el ZOOM en la escuela. Hice nuevos vínculos, amistades, profesores y profesoras. Agradezco al COVID por darme todo eso. Es lo que siento en mi corazón gracias al ZOOM (Roby, abril de 2021). 
Revista de la Escuela de Ciencias de la Educación. 2022, Año 18 1(17). 61-77. Enero a junio. Schwamberger, C. Lo que la pandemia nos quitó: relatos de estudiantes con discapacidad intelectual en tiempos de COVID-19.

Sentir desde el corazón y enunciarse desde el deseo, entre muertes, desastres y luchas, para revincularse y estar con otros, vuelve aquí la lectura de Levinas (1997), de necesitar(nos) y la posibilidad de narrarnos entre experiencias que enmudecen (Benjamin, 1999). En relación al diálogo que establece, con sus pares y sus docentes, mediante el ZOOM que organizan durante la semana, Roby menciona un actor central para que ello ocurra:

mi mamá tiene un grupo que hizo la de inclusión y nos ayuda desde ahí, nos manda trabajo, la mayoría son de matemáticas, descargamos la hoja y tiene la actividad y lo hacemos (...) Es una gran maestra, una gran profesora de inclusión porque cuando no vino la maestra de matemática ese día, que era presencial, se puso en el pizarrón a dar clase y nos ayudó. No da clases virtuales, todo por el celular a través del grupo que tienen con mamá, algunas veces, no mucho, hacemos zoom y a veces me ayuda a través de ahí. (...) Es más si me dicen mis propias amigas que me digan que luche por ella, yo lucharía por ella mil veces hasta que caiga porque ella nos ayudó mucho. Adentro y fuera del salón, nos ayudó de verdad, le agradezco a ella por ayudarnos (Roby, abril de 2021).

El apoyo cotidiano de las familias, como relata, respecto del grupo de WhatsApp o los encuentros en las plazas que nos traía Pablo, son parte esencial de estos tiempos escolares. Experiencias invisibilizadas, que discurren entre acuerdos individuales y colectivos para sostener algo de la escolaridad y su continuidad. Asimismo, la figura del docente de apoyo a la inclusión se vuelve clave para acompañar trayectorias en los distintos niveles $y$, en particular, en aquellas disciplinas que requieren mayores niveles de abstracción, comprensión y concentración. Aquí nos interrogamos sobre su importancia. ¿Qué sería entonces de estudiantes como Roby, Pablo y tantos otros? ¿que encuentran múltiples escollos para transitar la escolaridad que sin contar con el acompañamiento doble o triple de estos actores clave (familias-profesores de nivel-docente de apoyo a la inclusión) la inclusión no sería posible? Poner en valor estas experiencias, a través de relatos de sus protagonistas, aporta una mirada otra acerca de cómo se vive y se transita la escolaridad en el nivel secundario.

\section{Discusiones}

La inclusión de estudiantes con discapacidad en el nivel secundario guarda estrictas relaciones sobre los modos en que fue pensado y diagramado el nivel. La masificación de la matrícula estuvo caracterizada, por un antes y un después, a partir de la Ley de Educación Nacional No 26.206/2006 que, en su artículo 16 estable la obligatoriedad, así como su universalidad. Dadas las limitantes del escrito, no ahondaremos en las particularidades que asume la escolarización secundaria que ha sido extensamente desarrollada (Nobile, 2016; Southwell, 2020). Sin embargo, nos centramos en la posibilidad de analizar cómo, bajo los efectos del COVID-19 y las desigualdades pre-existentes, un gran conjunto de la población estudiantil, encuentra alterada su permanencia, más aún, cuando nos referimos a estudiantes con discapacidad intelectual que, como mencionamos, son categorizados en términos de abyección. 
Revista de la Escuela de Ciencias de la Educación. 2022, Año 18 1(17). 61-77. Enero a junio. Schwamberger, C. Lo que la pandemia nos quitó: relatos de estudiantes con discapacidad intelectual en tiempos de COVID-19.

Ante la multiplicidad de obstáculos que transitan los estudiantes con discapacidad, se suma otro factor potenciador de nuevas limitantes para lograr procesos de enseñanza y de aprendizaje. Esta limitante, como factor global, restringe las posibilidades de todos, pero afecta de manera particular a los colectivos más excluidos (Bochio, 2020; Marsollier y Expósito, 2021; Tapia y Meléndez, 2021), que, como mencionan Grinberg y Verón (2021), la pandemia COVID-19 afecta en un marco desproporcionado de reconocimiento diferencial. Esto obliga a las instituciones y a los sujetos, a tener que hacerse cargo de manera individualizada, como lo relata Roby, respecto del acompañamiento que brinda su docente de apoyo a la inclusión, con el objeto de sostener recorridos y experiencias potentes de inclusión.

Ese reconocimiento diferencial de derechos (Butler, 2006) que plantean los autores (Grinberg y Verón, 2021), como la noción "derecho a tener derechos" (p.233), que retoman de Arendt, repercute en el modo en que los estudiantes aprenden y los docentes enseñan. Lo anterior, en condiciones materiales altamente precarias, se vuelve una encrucijada más para acceder al derecho a la educación y sostener trayectorias en un marco de obligatoriedad. Ello, como mencionan Tapia y Meléndez (2020),

La pandemia incrementó el distanciamiento social entre aquellos que pueden acceder a lo que el mercado de la virtualización pone a disposición de la educación y aquellos que no pueden dejar de prescindir de la escuela con las puertas abiertas, el docente que abraza y calma el sufrimiento que causa la desigualdad (p.68).

Así, transitar la escuela secundaria como lo mencionan Roby y Pablo depende exclusivamente de los recursos que en sus hogares dispongan. Hogares que como relatan, muchas veces, no poseen condiciones dignas habitacionales ni los servicios básicos de luz, gas o conexión a internet, situación que restringe las posibilidades y el acceso a educarse (Machado, 2020). Este desamparo, que fue compensado por acciones institucionales y docentes, repuso los principios educativos de la inclusión en esa máxima del derecho a tenerlo (Grinberg y Verón, 2021).

En este punto sostenemos, fuertemente, que la inclusión fue posible a partir de las acciones sostenidas -no sin obstáculos y exclusiones- que desplegaron los docentes tanto de las escuelas secundarias como los docentes de apoyo a la inclusión. En palabras de Roby, esto se traduce en aquello que menciona como "tengo la mejor docente de inclusión del mundo y si tengo que luchar por ella lo hago hasta la muerte". Al respecto, Dubrovsky y Lanza (2019), sostienen que, en experiencias de inclusión, no sólo se confirma la dificultad, sino que se remueven prejuicios y estigmas enquistados que corroen los modos hegemónicos y homogéneos de pensar la escolaridad. Sobre este punto es preciso analizar estos procesos desde la perspectiva de los profesores de cada una de las materias disciplinares que será la base de futuras indagaciones.

Uno de los ejes en debate, por cierto, que adquiere centralidad en los relatos de los estudiantes, se vincula con la necesidad de la vuelta a la presencialidad. Si bien Roby menciona que "la escuela está en todos lados", la 
Revista de la Escuela de Ciencias de la Educación. 2022, Año 18 1(17). 61-77. Enero a junio. Schwamberger, C. Lo que la pandemia nos quitó: relatos de estudiantes con discapacidad intelectual en tiempos de COVID-19.

presencialidad, la necesidad de volver a la escuela, en este caso, es demandada fuertemente por los estudiantes. Como apuntan Espinosa Parra, Maldonado Regalado y Rosero Poma (2020), ponen en discusión que la tan aclamada necesidad de "nueva o antigua normalidad" rebosa en le reproducción de prácticas y experiencias enquistadas en principios normalizadores y excluyentes.

En ese punto, refieren que "regresar a la antigua normalidad, sería retornar a un currículo muy bibliográfico y abundante de contenidos redundantes" (p. 227). En esta misma línea, como algo promisorio, durante la pandemia se priorizaron determinados contenidos que posibilitaron ciertas flexibilizaciones y re-configuraciones del currículum. Lo anterior, podría pensarse como apoyos posibles de ser sostenidos en el porvenir. Todo aquello que la pandemia nos dejó o nos deja, podría revisarse a la luz de garantizar proyectos de inclusión más heterogéneos y flexibles con un currículum más accesible para todos y cada quien (Echeíta, 2020; Murillo y Duk, 2020).

\section{CONCLUSIÓN}

En este trabajo propusimos un debate respecto de los procesos de inclusión de estudiantes con discapacidad, en el nivel secundario, en escuelas públicas de gestión estatal ubicadas en espacios del territorio marcados por la pobreza y la contaminación ambiental. Asimismo, realizamos un breve estado de situación de la puesta en marcha y ejecución de las distintas normativas que amparan el derecho a la educación, de las personas con discapacidad, en los distintos niveles y modalidades del sistema educativo. Recuperamos distintas investigaciones y estudios recientes que aportan datos cuantificables sobre el modo en que la inclusión se despliega en nuestro territorio. Esto, a los efectos de ofrecer un lente analítico en relación a las trayectorias de estudiantes, en tiempos pandémicos, que, como mencionamos, aún no encontramos experiencias de cómo ello ocurre efectivamente.

Ante esta vacancia recuperamos relatos, a través de las voces de los protagonistas, en particular, dos estudiantes con discapacidad intelectual que transitan el primer y segundo año del nivel secundario. Ello, nos acerca a una mirada otra de cómo viven su experiencia escolar en estos tiempos. Si bien, los obstáculos se maximizan debido a las condiciones materiales precarias y, en particular, a las dificultades de conexión y de vínculos con los otros, Roby y Pablo, aportan otra cara de la misma moneda. Es decir, con aquello que se encuentra silenciado de los discursos y enunciados que las políticas de inclusión traen consigo. En sus voces encontramos esas intensidades de los debates binomiales que se expresan, también, entre querer volver a la escuela, porque así es más difícil y, entre tener a la escuela por zoom para preservar sus vidas.

Finalmente, ¿cómo pensar entonces, los escenarios venideros para garantizar procesos de inclusión, en estos contextos, que recae en los esfuerzos y acciones colectivas que se encarnan en una tríada indisociable familiaestudiante-docentes?, ¿dónde están y como son esos relatos que aún no conocemos, que no llegan a la escuela y que desde el 16 de marzo de 2020 su presencia escolar es exclusivamente para la búsqueda de un bolsón alimentario? Y una pregunta no menos significativa respecto de los modos en que la 
Revista de la Escuela de Ciencias de la Educación. 2022, Año 18 1(17). 61-77. Enero a junio. Schwamberger, C. Lo que la pandemia nos quitó: relatos de estudiantes con discapacidad intelectual en tiempos de COVID-19.

bimodalidad afectará los procesos de enseñanza y aprendizaje. Surgen más interrogantes que respuestas y es allí donde nuestros esfuerzos tienen que dirigirse.

\section{REFERENCIAS}

Barrozo, N. (2018). Educación Secundaria y discapacidad: entre la obligatoriedad, igualdad e inclusión. RUEDES, (8), 32-47. https://revistas.uncu.edu.ar/ojs/index.php/ruedes/article/view/1658

Barton, L. (2008). Superar las barreras de la discapacidad. Morata.

Benjamin, W. (1991). El narrador. Tauros.

Bocchio, M. C. (2020). El futuro llegó hace rato: pandemia y escolaridad remota en sectores populares de Córdoba, Argentina. Revista Internacional de Educación para la Justicia Social, $9(3)$. https://revistas.uam.es/riejs/article/view/12473

Bolívar, A. (2002). ¿De nobis ipsis silemus?: Epistemología de la investigación biográfico-narrativa en educación. Revista Electrónica de Investigación Educativa 4(1).http://redie.uabc.uabc.mx/vol4no1/contenido-bolivar.html

Butler, J. (2006). Vida precaria. El poder del duelo y la violencia. Paidós.

Butler, J. (2010). Marcos de Guerra. Las vidas Iloradas. Paidós.

Butler, J. (2018). Cuerpos que importan. Sobre los límites materiales y discursivos del "sexo". Paidós.

Cinquegrani, M. (2021). "¿Dónde está lo que falta?" Representaciones y miradas acerca de la discapacidad en la escuela a partir de las narrativas de familias en lucha por el derecho a la educación inclusiva en la provincia de Buenos Aires (2006-2017). Pasado Abierto 713). https://fh.mdp.edu.ar/revistas/index.php/pasadoabierto/article/view/472 $4 / 5369$

Connelly, M. y Clandinin, J. (1995). Relatos de experiencia e investigación educativa, en J. Larrosa et. al. (comps.) Déjame que te cuente. Ensayos sobre narrativa y educación, 11-59. Laertes.

Danel, P. M. (2021). Discapacidad, infancias y desigualdades en el Gran La Plata. Cátedra Paralela, (18), 57-79. https://doi.org/10.35305/cp.vi18.269

De Certeau, M. (2003). La invención de lo cotidiano. UIA.

De Sena, A. (2015). Caminos cualitativos: aportes para la investigación en ciencias sociales. CICCUS.

Dubrovsky, S., y Lanza, C. (2019). Prácticas inclusivas en el nivel secundario: la experiencia desde la perspectiva de una estudiante con discapacidad. Revista De La Escuela De Ciencias De La Educación, 1(14). https://doi.org/10.35305/rece.v1i14.403

Echeita, G. (2020). La Pandemia del Covid-19. ¿Una Oportunidad para Pensar en Cómo Hacer más Inclusivos Nuestros Sistemas Educativos? Revista Internacional De Educación Para La Justicia Social, 9(1). https://revistas.uam.es/riejs/article/view/12152

Espinoza Parra, C. N.; Maldonado Regalado, G. A. \& Rosero Poma, C. J. (2020). Los desafíos de la inclusión en tiempos de COVID-19. Revista Scientific, 
Revista de la Escuela de Ciencias de la Educación. 2022, Año 18 1(17). 61-77. Enero a junio. Schwamberger, C. Lo que la pandemia nos quitó: relatos de estudiantes con discapacidad intelectual en tiempos de COVID-19.

5(17), 221-239. https://doi.org/10.29394/Scientific.issn.25422987.2020.5.17.11.221-239

Ferrante, C. (2020). La "discapacidad" como estigma: una mirada social deshumanizante. Una lectura de su incorporación temprana en los Disability Studies y su vigencia actual para América Latina. Revista Pasajes, 10, 1-26. https://revistapasajes.site/2020/02/numero-10-enero-junio$2020 /$

Fondo de las Naciones Unidas para la Infancia (UNICEF). (2020). La resolución 311/16 en la Argentina. Análisis y guía para su mejor implementación. https://www.unicef.org/argentina/publicaciones-y-datos/resolucion-31116-en-Argentina

Galván, M. (2018). Trayectorias escolares de jóvenes con discapacidad en la educación secundaria obligatoria. Trabajo final integrador. Universidad Nacional de La Plata. Facultad de Humanidades y Ciencias de la Educación. www.memoria.fahce.unlp.edu.ar/tesis/te.1668/te.1668.pdf

Gerber, D. (2008). Escuchar a las personas con discapacidad. El problema de la voz y la autoridad en el libro de Robert B. Edgerton en L., Barton, Superar las barreras de la discapacidad. 275-298. Morata.

Glaser y Strauss (1967). The discovery of grounded theory. Aldine Publishing Company

Grinberg, S. (2020). Etnografía, biopolítica y colonialidad. Genealogías de la precariedad urbana en la Región Metropolitana de Buenos Aires. Tábula Rasa, 34, 19-39. DOI: https://doi.org/10.25058/20112742.n34.02

Grinberg, S. y Armella, J. (2021). Cartografías de la mirada otra: Jóvenes, pobreza urbana y producción audiovisual en la era postmedia. Praxis educativa, 25(1) 1-18. https://dx.doi.org/10.19137/praxiseducativa-2021250106

Grinberg, S. y Verón, E. (2021). \#COVID-19: Shock y el derecho a tener derechos en las periferias metropolitanas. Un estudio en la Región Metropolitana de Buenos Aires en L. Peña et. al., Pandemia y crisis: el COVID-19 en América Latina, 231-257. Editorial Universidad de Guadalajara.

Levín Rojo, E., y Denys Espinoza, M. (2009). Enunciar(se) desde la discapacidad. Argumentos 22(61),

141-156. https://www.redalyc.org/articulo.oa?id=59512092007

Levinas, E. (1993). El tiempo y el otro. Paidós.

Lopes, M.C. (2011). Políticas de inclusão e governamentalidade en A. Thoma; B. Hillesheim (orgs.). Políticas de inclusão: gerenciando riscos e governando as diferenças, 7-15. EDUNISC

Machado, M. (2020). Investigar y seguir haciendo escuela presente en contextos de pobreza urbana en tiempos de COVID. Educación y Vínculos, 2(6), 102 - 117. http://pcient.uner.edu.ar/EyV/article/view/866

Marsollier, R. G., y Expósito, C. D. (2021). Nuevas necesidades educativas. Una aproximación a los condicionantes del Sistema Educativo en épocas de confinamiento social. Revista De La Escuela De Ciencias De La Educación, 1(16), 1-10. https://doi.org/10.35305/rece.v1i16.579 
Revista de la Escuela de Ciencias de la Educación. 2022, Año 18 1(17). 61-77. Enero a junio. Schwamberger, C. Lo que la pandemia nos quitó: relatos de estudiantes con discapacidad intelectual en tiempos de COVID-19.

Moriña Diez, A. (2010). Vulnerables al silencio. Historias escolares de jóvenes con discapacidad. Revista de Educación, (353) 667-690. http://www.revistaeducacion.educacion.es/re353/re353_25.pdf

Murillo, F. Javier, y Duk, Cynthia. (2020). El COVID-19 y las Brechas Educativas. Revista latinoamericana de educación inclusiva, 14(1), 11-13. https://dx.doi.org/10.4067/S0718-73782020000100011

Nobile, M. (2016). La escuela secundaria obligatoria en Argentina: Desafíos pendientes para la integración de todos los jóvenes. Última década, 24(44), 109-131. https://dx.doi.org/10.4067/S0718-22362016000100005

Porta, L. (2021). La expansión biográfica. Editorial de la Facultad de Filosofía y Letras Universidad de Buenos Aires. http://publicaciones.filo.uba.ar/sites/publicaciones.filo.uba.ar/files/NAyE \%20V\%20-La\%20expansion\%20biografica_interactivo.pdf

Rosato, A. y Angelino, M.A. (coords.). (2009). Discapacidad e ideología de la normalidad. Desnaturalizar el déficit. Noveduc.

Schewe, L. (2021). Trayectorias escolares de estudiantes con discapacidad: logros, obstáculos y desafíos en la educación secundaria. Tesis de Doctorado. Universidad Nacional de la Plata. http://sedici.unlp.edu.ar/handle/10915/117194

Schwamberger, C. y Grinberg, G. (2020). Devenir escuela colador: dinámicas de escolarización de estudiantes con discapacidad en contexto de pobreza urbana de la RMBA. Praxis educativa 24(2), 1-15. DOI: https://dx.doi.org/10.19137/praxiseduc ativa-2020-240202

Skliar, C. (2011). Diez escenas educativas para narrar lo pedagógico entre lo filosófico y lo literario. Revista Plumilla Educativa, 8, 11-22.

Suárez, D. (2007). Docentes, narrativa e investigación educativa. La documentación narrativa de las prácticas docentes y la indagación pedagógica del mundo y las experiencias escolares en I. Sverdlick (comps.). La investigación educativa: una herramienta de conocimiento y acción, 71-110. Noveduc.

Tapia, M.G. y Meléndez, C. (2020). Escuela secundaria en tiempos de pandemia: La fragmentación del sistema educativo al descubierto. Nuevas Propuestas 5 (XXXIX) 60-69. http://ediciones.ucse.edu.ar/ojsucse/index.php/nuevaspropuestas/article /view/21/19

Thoma, A. (in memoriam); Hillesheim, B.; de Freitas Corrêa Siqueira, C. (2019). Inclusão, diferença e políticas públicas. EDUNISC. https://repositorio.unisc.br/jspui/bitstream/11624/2719/1/Inclus\%C3\%A 30\%2C\%20diferen\%C3\%A7a\%20e\%20pol\%C3\%ADticas\%20p\%C3\%BA blicas.pdf

Walmsley, J. (2008). Normalización, investigación emancipadora e investigación inclusiva en el ámbito de la discapacidad intelectual en L. Barton (2008). Superar las barreras de la discapacidad, 329-380. Morata.

Yuni, J.A. (2021). Dilemas de la investigación como práctica institucional y experiencia biográfica. Praxis educativa, 25(1), 1-21. https://dx.doi.org/10.19137/praxiseducativa-2021-250105 